\title{
Combined therapy of colon carcinomas with an oncolytic adenovirus and valproic acid
}

\author{
Christian Bressy ${ }^{1}$, Dragomira Majhen ${ }^{1}$, Najat Raddi ${ }^{1}$, Wael Jdey ${ }^{1}$, Gaétan \\ Cornilleau $^{1}$, Léna Zig ${ }^{1}$, Josée Guirouilh-Barbat ${ }^{2}$, Bernard S. Lopez ${ }^{2}$, Olivia Bawa ${ }^{3}$, \\ Paule Opolon $^{3}$, Elodie Grellier ${ }^{1}$ and Karim Benihoud ${ }^{1}$ \\ ${ }^{1}$ Vectorologie et Thérapeutiques Anticancéreuses, UMR 8203 CNRS, Université Paris-Sud, Gustave Roussy, Université Paris- \\ Saclay, Villejuif 94805, France \\ ${ }^{2}$ Laboratoire Recombinaison-Réparation et Cancer, UMR 8200 CNRS Stabilité Génétique et Oncogenèse, Université Paris- \\ Sud, Gustave Roussy, Université Paris-Saclay, Villejuif 94805, France \\ ${ }^{3}$ Unité de pathologie expérimentale de I'IRCIV, Gustave Roussy, Villejuif 94805, France \\ Correspondence to: Karim Benihoud, email: karim.benihoud@gustaveroussy.fr \\ Keywords: colon; polyploidy; oncolytic adenovirus; DNA damage; HDACi \\ Received: November 25, $2016 \quad$ Accepted: August 04, $2017 \quad$ Published: October 26, 2017 \\ Copyright: Bressy et al. This is an open-access article distributed under the terms of the Creative Commons Attribution License 3.0 \\ (CC BY 3.0), which permits unrestricted use, distribution, and reproduction in any medium, provided the original author and source \\ are credited.
}

\section{ABSTRACT}

The anti-tumor potential of oncolytic adenoviruses (CRAds) has been demonstrated in preclinical and clinical studies. While these agents failed to eradicate tumors when used as a monotherapy, they may be more effective if combined with conventional treatments such as radiotherapy or chemotherapy. This study seeks to evaluate the combination of a CRAd bearing a $\Delta 24$ deletion in E1A with valproic acid (VPA), a histone deacetylase inhibitor, for the treatment of human colon carcinomas. This combination led to a strong inhibition of cell growth both in vitro and in vivo compared to treatment with CRAd or VPA alone. This effect did not stem from a better CRAd replication and production in the presence of VPA. Inhibition of cell proliferation and cell death were induced by the combined treatment. Moreover, whereas cells treated only with CRAd displayed a polyploidy ( $>4 \mathrm{~N}$ population), this phenotype was increased in cells treated with both CRAd and VPA. In addition, the increase in polyploidy triggered by combined treatment with CRAd and VPA was associated with the enhancement of H2AX phosphorylation (YH2AX), a hallmark of DNA damage, but also with a decrease of several DNA repair proteins. Finally, viral replication (or E1A expression) was shown to play a key role in the observed effects since no enhancement of polyploidy nor increase in YH2AX were found following cell treatment with a replication-deficient Ad and VPA. Taken together, our results suggest that CRAd and VPA could be used in combination for the treatment of colon carcinomas.

\section{INTRODUCTION}

Colorectal cancer (CRC) is the third most common cancer worldwide, with about one million new cases diagnosed and 600,000 deaths per year [1]. Treatment of colon cancer typically involves surgical removal of all or a portion of the colon and may result in serious side effects such as infections, bleeding, and injury to adjacent organs. Surgery may also fail to eliminate metastatic lesions. Chemotherapy and radiotherapy are commonly used as adjuncts to surgery with only minor impact on the overall survival time of the patients [1]. Therefore, new therapies are needed to cure CRC. Recently, virotherapy and treatment with histone deacetylase inhibitors have emerged as useful therapeutic approaches.

Virotherapy uses viruses called oncolytic viruses, which selectively replicate in and kill tumor cells. Several groups have developed oncolytic vectors based on human 
adenoviruses (Ads) [2, 3] and known as conditionally replicative adenovirus (CRAd). Their tumor selectivity is achieved by controlling viral genome replication with a tumor-specific promoter such as the promoter of telomerase or prostate-specific antigen. Alternatively, selectivity may be obtained by specific deletions within the viral genome. For example, Onyx-015, a type 5 human adenovirus (Ad5) with a deletion in the gene encoding E1B-55kDa protein, replicates selectively in tumors and received regulatory approval in China in the treatment of head and neck cancer $[4,5]$. Also, Ads bearing a 24-bp deletion in the E1A region, which prevents interaction with $\mathrm{pRb}$ protein, have been shown to replicate in tumor cells that have impairment in the $\mathrm{pRb}$ pathway, with minimal replication in post-mitotic cells [6, 7]. Finally, following either direct intratumoral or systemic administration, several pre-clinical and clinical studies have demonstrated the capacity of oncolytic Ads to reduce CRC growth while being well-tolerated [8-11]. Despite these achievements, the efficacy of CRAds is limited by poor transduction of tumor cells, neutralization by the host's immune system, interaction with blood components, and failure to efficiently spread into tumors $[3,12]$.

Several strategies have been used to increase the potential of CRAds for the treatment of CRC. For example, CRAds have been armed with a transgene carrying anti-angiogenic functions [13] or with a suicide gene such as cytosine deaminase [14]. Another approach has been to enhance the efficacy of CRAds by combining them with radiotherapy as described for Onyx-015 [5]. More recently, CRAds have been combined with different chemotherapeutic agents (for a review see [15]). For example, the combination of CRAd with 5-fluorouracil [16] or everolimus, an mTOR inhibitor [17], demonstrated enhanced anti-tumor effects in CRC models. Also, in different non-CRC tumor models, histone deacetylase (HDAC) inhibitors have been shown to potentiate CRAds by upregulating Ad5 primary receptors [18] or transgene expression [19].

Histone deacetylases (HDACs) and histone acetyl transferases (HATs) are involved in epigenetic gene regulation. The different classes of HDACs (I, IIa, IIb, III and IV) deacetylate both histones and non-histone proteins. By doing so, they modulate transcription by increasing the level of chromatin compaction, thereby reducing the accessibility of transcription factors to DNA [19]. Interestingly, class I HDACs 1, 2 and 8 have been shown to be overexpressed in colon-derived tumors [20, 21]. HDAC inhibitors (HDACi) are small molecules able to promote histone acetylation by modifying the balance between HDACs and HATs [22]. Their cellular effects include growth arrest through the expression of cyclinkinase inhibitors, as well as the triggering of apoptotic and cell differentiation pathways, inhibition of angiogenesis, and the activation of anti-tumor immune responses [20]. Among HDACi, valproic acid (valproate, VPA) is a well- established drug used over three decades for the longterm therapy of epilepsy. VPA acts as a specific inhibitor of class I and IIa HDACs and induces proteasomal degradation of HDAC2 [23]. VPA is able to trigger growth arrest and apoptosis in vitro in colon carcinomas [24] and reduce adenoma formation in $\mathrm{APC}^{\mathrm{Min}}$ mice model [21].

In this study, we examine the potential of combining a CRAd and VPA for the treatment of colon carcinoma. We provide evidence that these compounds in combination inhibited CRC growth in vitro; and that this effect is not due to an increased CRAd replication but is associated with cell cycle modifications, H2AX phosphorylation, decrease of DNA repair proteins, and polyploidy. Most interestingly, we provide in vivo evidence that the combined treatment provoked a stronger reduction of tumor growth compared to single treatments.

\section{RESULTS}

\section{Reduction of colon carcinoma cell line growth after combined treatment with a CRAd and VPA}

In order to improve CRC treatment, we examined whether the combined use of AdE1 $\triangle 24$ (below referred as CRAd) and VPA, a drug already in clinical use, could produce a stronger effect than CRAd or VPA alone. First, using MTT assays we determined VPA doses (Supplementary Table 1) able to reduce the growth of different CRC cell lines (HT29, HCT116, SW480 and SW620). For the continuation of our study we used VPA doses corresponding to IC50 and IC25 for each cell line individually. Then, cells were infected with different MOI of CRAd without or with VPA. After 3 days, a dosedependant decrease in cell growth for all cell lines, both in crystal violet (Figure 1A) and MTT (Figure 1B) assays, was observed after treatment with CRAd alone, with HCT116 being less sensitive to the virus in comparison to the other cell lines. Compared to the treatment with CRAd or VPA alone, all cell lines treated with both CRAd and VPA displayed a strong reduction in cell growth at MOI ranging from 0.98 up to $62.5 \mathrm{vp} / \mathrm{cell}$. In addition, at these MOI, the reduction in cell growth was more severe with the highest VPA dose (Figure 1B). Specific experiments were performed to assess the synergistic/ additive interaction between CRAd and VPA using the Chou-Talalay method [25]. CRAd or/and VPA were added at 0.125 to 2 times their IC50 and cell viability was measured using an MTT assay. Data were used to calculate $\mathrm{CI}$ using the Compusyn program. At most tested doses (except higher doses for HCT116), CRAd and VPA reduce cell growth in an additive manner for HT29, HCT116 and SW620. Interestingly, the combination has a synergistic effect in SW480 at different concentrations of the agents (Supplementary Figure 1).

To get insight into the effects of CRAd and VPA combination, we monitored HT29 and HCT116 growth 
for 3 days after treatment with CRAd, VPA or both (Figure 1C) by MTT assay. A 4-fold increase in cell growth at day 3 was observed in non-treated cells compared to day 1, while cells treated with CRAd or VPA alone showed a 2- to 3-fold increase in cell growth. Interestingly, the combination of CRAd and

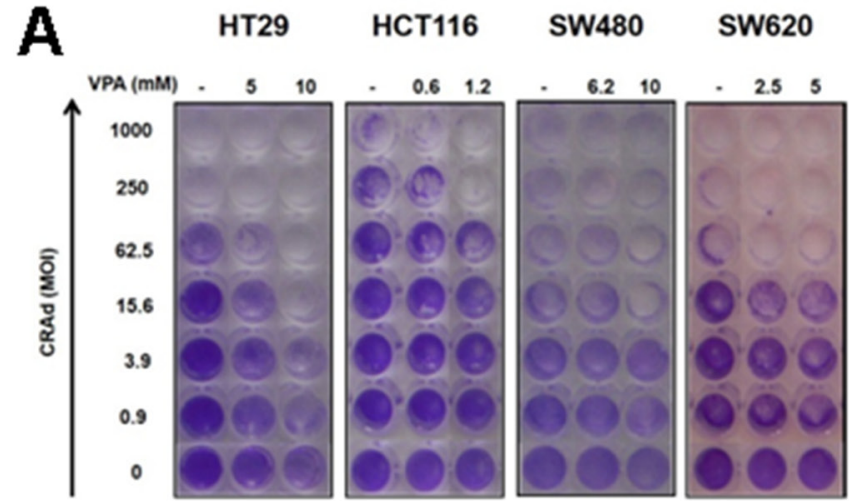

B
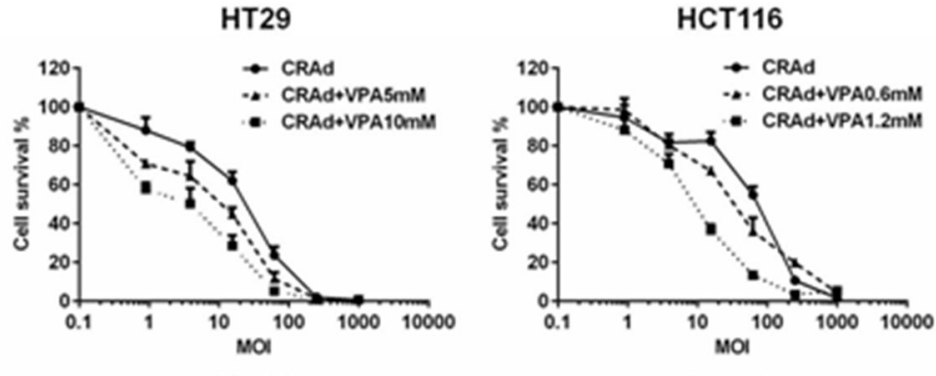

SW480
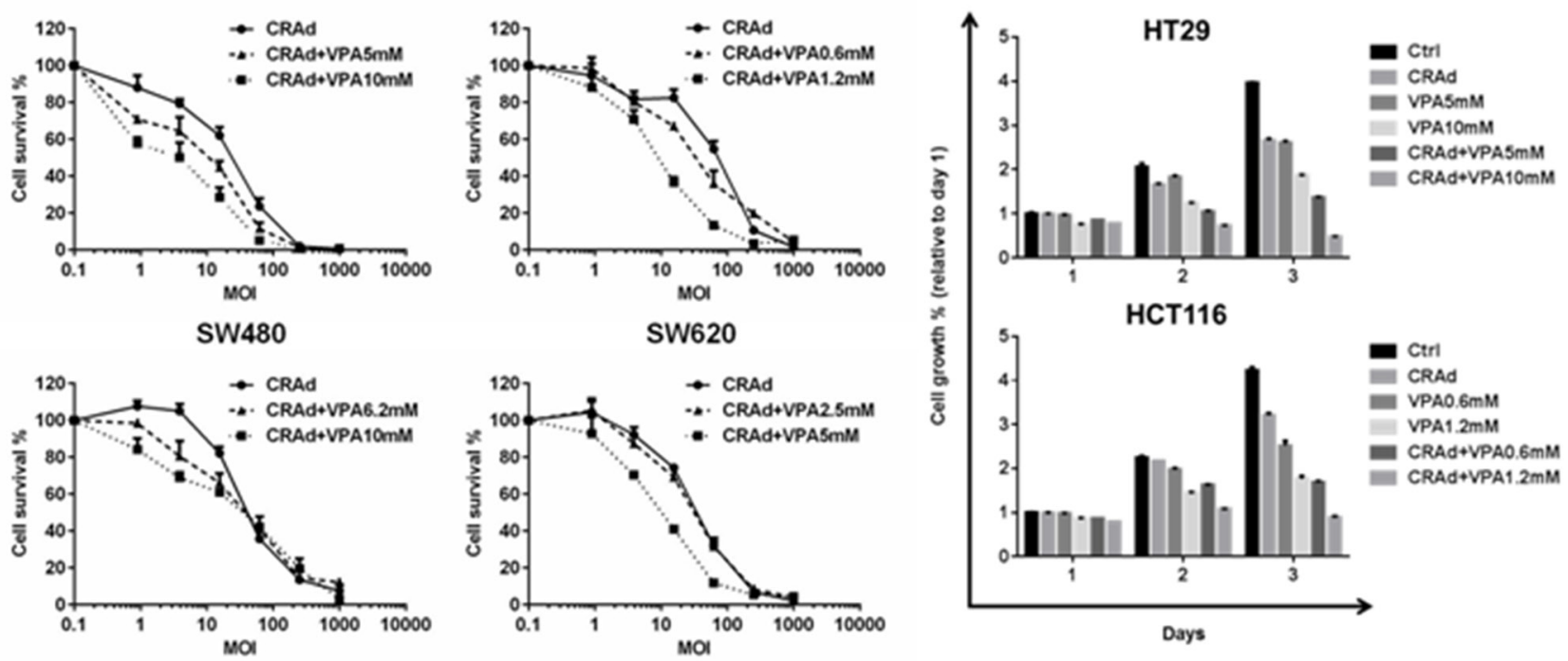

$\mathbf{D}$
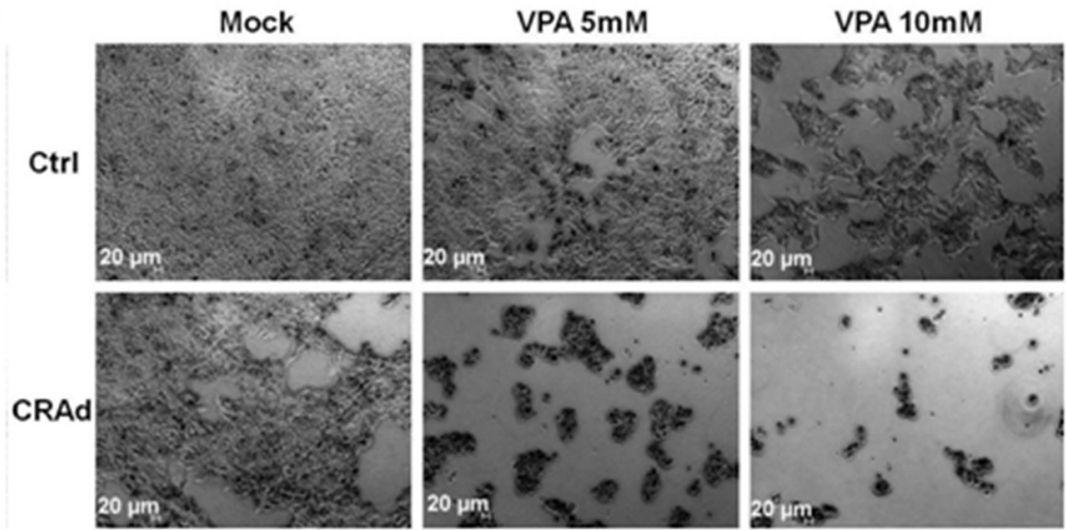

Figure 1: Reduced growth of CRC cell lines after combined treatment with CRAd and VPA. CRC cell lines (HT29, HCT116, SW480 and SW620) were infected with different MOI of CRAd (ranging from 0 to $1000 \mathrm{vp} / \mathrm{cell}$ ) or treated with VPA (IC25 and IC50) or a combination of CRAd and VPA. Cell survival at day 3 was measured by crystal violet (A) or MTT (B) assays. (C) Growth of HT29 and HCT116 was assessed for 3 days by a MTT assay and expressed relative to non-treated cells at day 1. (D) After 3 days of treatment, HT29 cells were observed by phase-contrast microscopy. The results are representative of at least two experiments. 
VPA almost completely inhibited HT29 cell growth (Figure 1C).

On microscopic observation at day 3 , while nontreated HT29 cells appeared as a confluent monolayer, a reduced cell number was observed for VPA- or CRAd-only-treated HT29 cells. A dramatic decrease in the number of attached cells was observed after combined treatment with CRAd and VPA (Figure 1D and Supplementary Figure 2) in different cell lines. For all cell lines, the reduction of cell number after treatment with CRAd and VPA was confirmed by cytometry analysis (Supplementary Figure 3).

We also examined the combination of Ad $\beta g a l$, a non-replicative recombinant $\mathrm{Ad}$, and VPA in all
A

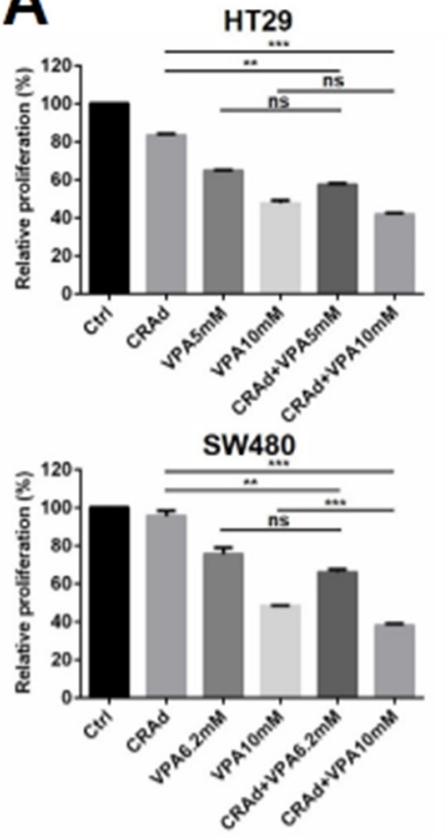

C
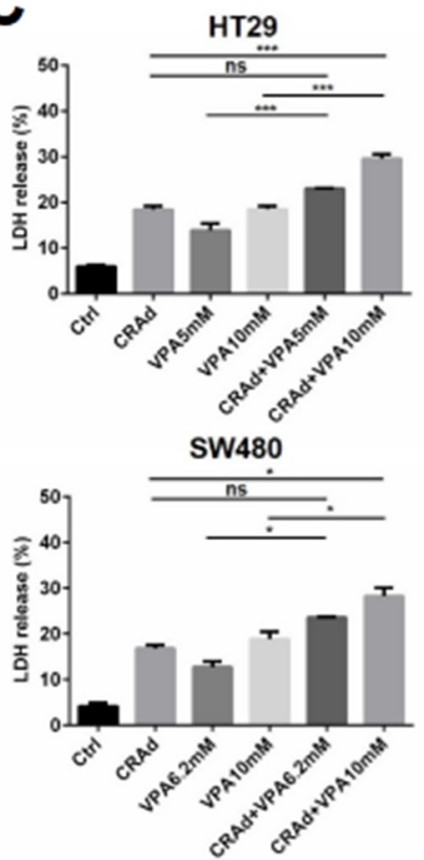
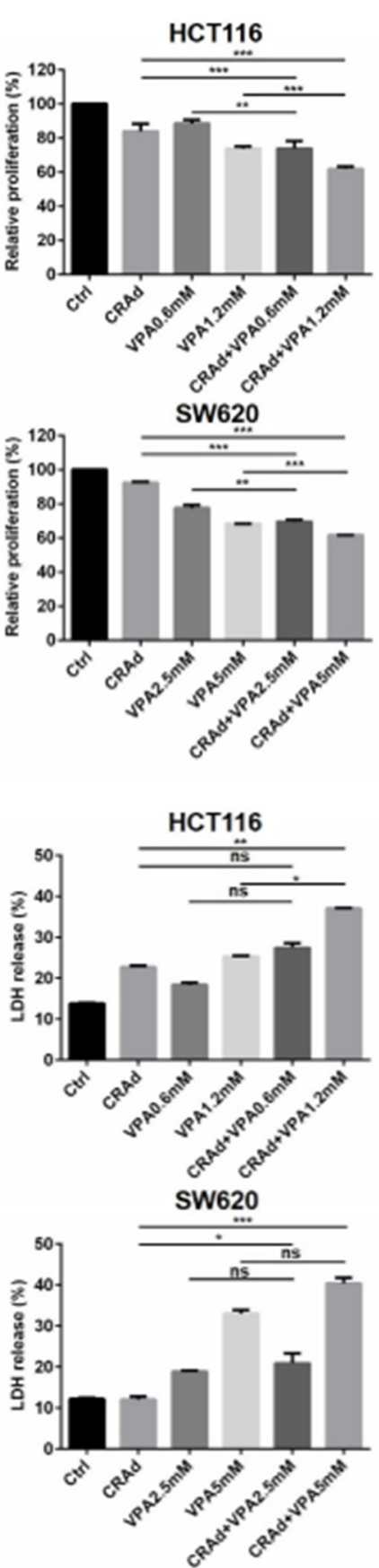

B

\section{HT29}

CRAd
VPA $5 \mathrm{mM}$

VPA $10 \mathrm{mM}$

p21

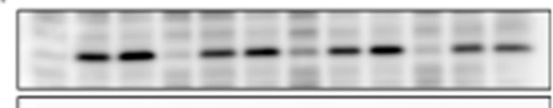

Tubulin

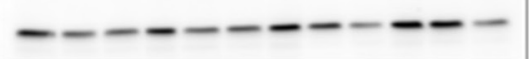

HCT116

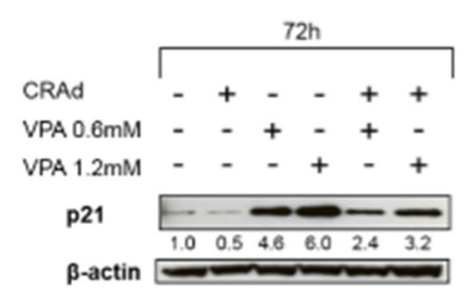

SW480

CRAd

VPA $6.2 \mathrm{mM}$

VPA $10 \mathrm{mM}$

p21

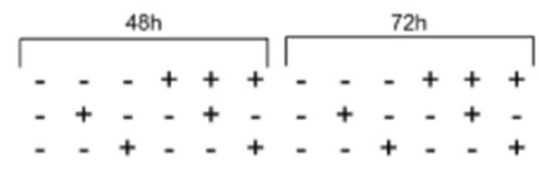

Tubulin

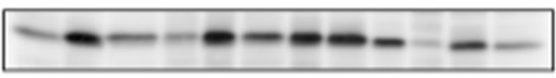

$---1-1-1$

Figure 2: Inhibition of proliferation and increase in cell death of CRC cell lines after combined treatment with CRAd and VPA. CRC cell lines (HT29, HCT116, SW480 and SW620) were infected with CRAd (MOI 15.6 vp/cell) with or without VPA (IC25 and IC50) or a combination of CRAd and VPA. (A) Relative proliferation index, (B) p21 expression in HT29, HCT116 and SW480, (C) $\mathrm{LDH}$ release were monitored at day 3. Data are from two experiments each performed in duplicate. Means $+\mathrm{SD} ; \mathrm{ns}, \mathrm{non}$ significant; ${ }^{*} P<$ $0.05 ;{ }^{* *} P<0.01 ;{ }^{* * *} P<0.001$. 
colon carcinoma cell lines. In sharp contrast to the results with CRAd and VPA, co-treatment of cells with Ad $\beta$ gal and VPA did not reduce cell survival compared to Adßgal-only-treated cells, suggesting that viral replication or E1 expression is required for the efficacy of CRAd and VPA combination (Supplementary Figure 4A). Furthermore, in contrast to the results observed with CRC cell lines, the co-treatment of prostatic (LNCaP) and renal (786-O) carcinoma-derived cell lines with CRAd and VPA did not reduce cell survival compared to CRAd-only-infected cells (Supplementary Figure 4B).

\section{Inhibition of cell proliferation and induction of cell death by CRAd and VPA combination}

To gain insight into the mechanism underlying the inhibition of cell growth by CRAd and VPA, we first determined the proliferation index of cells 3 days after treatment. Figure 2A shows that the co-treatment significantly reduced proliferation of different CRC cell lines, with the strongest reduction obtained at the highest VPA dose. In order to get insight on p21 status after CRAd and VPA co-treatment we performed western blot analyses on HT29, HCT116 and SW480 cells. In HT29 cells, no p21 expression was found in both Control and CRAd conditions consistent with previous reports [26]. In all three cell lines, CRAd infection led to a reduction of $\mathrm{p} 21$ expression compared to control conditions. Interestingly, in these cell lines, a strong dose-dependent induction of p21 by VPA with or without CRAd was found (Figure 2B). This upregulation of $\mathrm{p} 21$, a well-known inhibitor of cyclin-dependent kinase may contribute to the inhibition of cell proliferation. Next, we examined whether the co-treatment was able to trigger cell death. Interestingly, in all cell lines, compared to single treatments, CRAd and VPA combined treatment increased cell death as documented by $\mathrm{LDH}$ release (Figure 2C). Using annexin V (AV)-binding assay, a strong increase in $\mathrm{AV}^{+}$propidium iodide $(\mathrm{PI})^{+}$cells was observed in cells treated with CRAd and VPA, with no significant increase in $\mathrm{AV}^{+} \mathrm{PI}^{-}$cells (Supplementary Figure 5A). Western blot analyses performed on HT29 cell lysates showed no Parp-1 cleavage at day 2 whatever the treatment and low level of Parp-1 cleavage at day 3 after cotreatment with CRAd, VPA (high dose) and CRAd and VPA (high dose). No caspase-3 cleavage was found (Supplementary Figure 5B). These results suggest that apoptosis plays a minimal role in cell death after CRAd and VPA co-treatement.

Taken together, these results demonstrate that CRAd and VPA co-treatment inhibits cell growth through both inhibition of proliferation and induction of cell death.

\section{Transient delay in viral production after VPA treatment}

To investigate the molecular mechanism underlying the reduction of cell survival triggered by CRAd and VPA, we examined the ability of VPA to modulate CRAd production. Measurement of infectious virus particles by a TCID50 assay showed a slight, however not significant reduction of viral production at day 1 p.i. in all VPAtreated CRC cell lines (excepted SW620) compared to control-infected cells. Moreover, no statistical difference in viral production was observed at later time points (Figure 3A). Using western blot analyses, a comparable level of E1A proteins was detected in HT29 cells infected with CRAd with or without VPA (Figure 3B) ruling out a role for this drug on modulation of virus infection or early viral gene expression. In sharp contrast, the production of the fiber protein, a late Ad protein, was delayed in the presence of VPA in HT29 (24h and 48h), HCT116 (24h) and SW480 (48h and 72h)-infected cells (Figure 3C). Interestingly, this reduction in the level of a late protein was associated, with the exception of HCT116 cells, with a significant early reduction (day 1 ) in viral DNA cell content as documented by quantitative PCR (Figure 3D). However, viral genome cell content at later time points was not reduced by VPA treatment in accordance with the comparable viral production observed at these times in VPA-treated and non-VPA-treated cells (Figure 3D and $3 \mathrm{~A})$. Altogether, these data demonstrate that the increased cell death triggered by the combination of CRAd and VPA is not associated to an increased viral replication and production.

\section{Increase in cell ploidy in colon carcinomas following co-treatment with CRAd and VPA}

To better characterize the effects of the cotreatment on CRC cell lines, we examined their cell cycle distribution following treatment with VPA, CRAd or both. First, we showed that co-treatment with CRAd and VPA, as well as single treatments, did not trigger an increase in the proportion of cells in subG1 phase, thus eliminating a major role of apoptosis in cell death (Figure $4 \mathrm{~A}$ ) in accordance with AV PI assays (Supplementary Figure 5A) and Parp-1/caspase-3 western blot analyses (Supplementary Figure 5B). For both HT29 and HCT116 cell lines, CRAd-infection led to a reduction in G1 phase, and to a trend, even if not significant, to an increase in $\mathrm{G} 2 / \mathrm{M}$ and $>4 \mathrm{~N}$ phases. Interestingly, this $>4 \mathrm{~N}$ population was significantly increased after the combined treatment with CRAd and VPA compared to CRAd-only treated cells (Figure 4B). For example, in HCT116 cells treated with CRAd and VPA $1.2 \mathrm{mM}$, the proportion of $>4 \mathrm{~N}$ cells increased up to $48.4 \%$ compared to $22.8 \%$ after CRAd- 
A
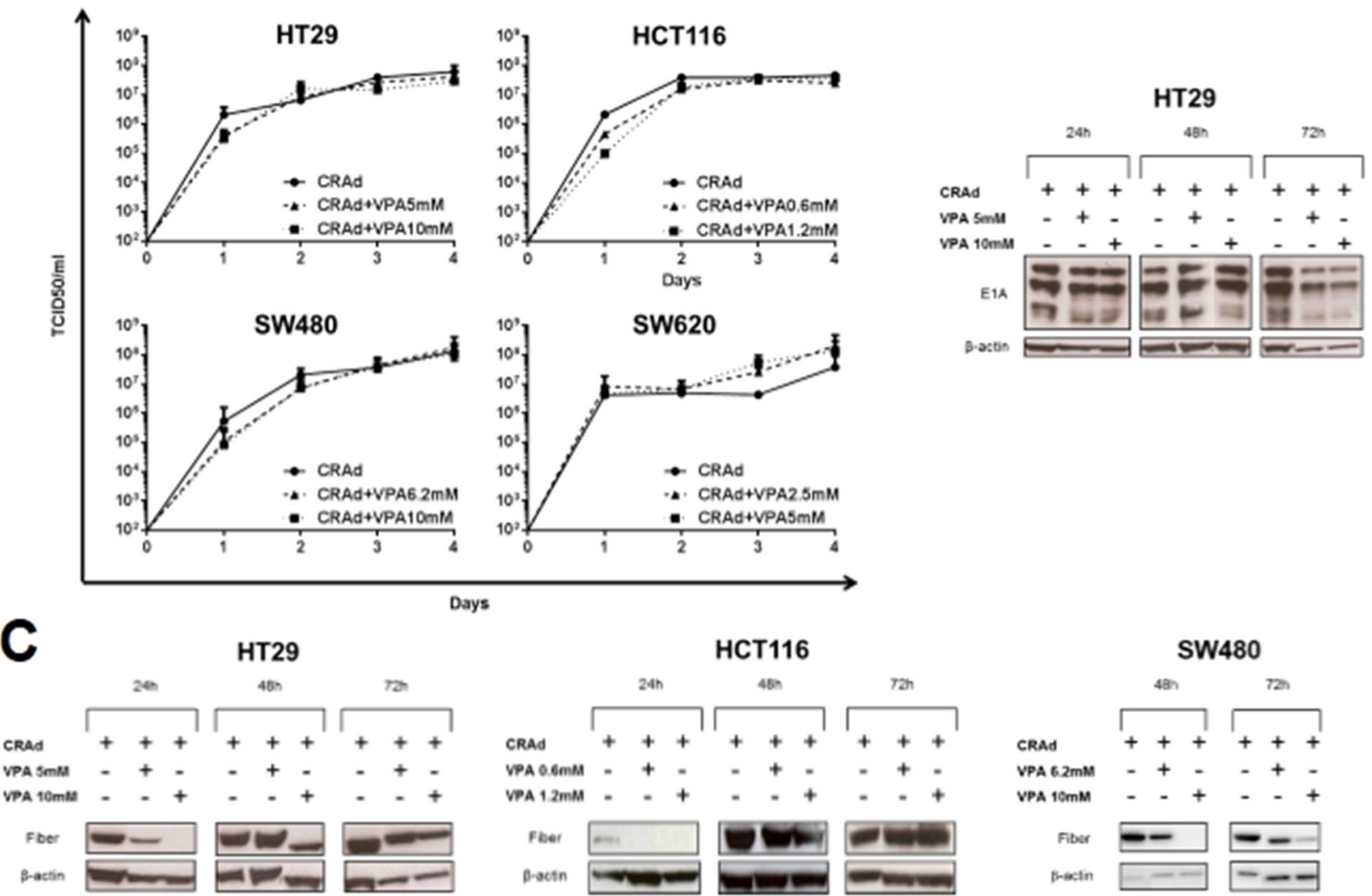

Days
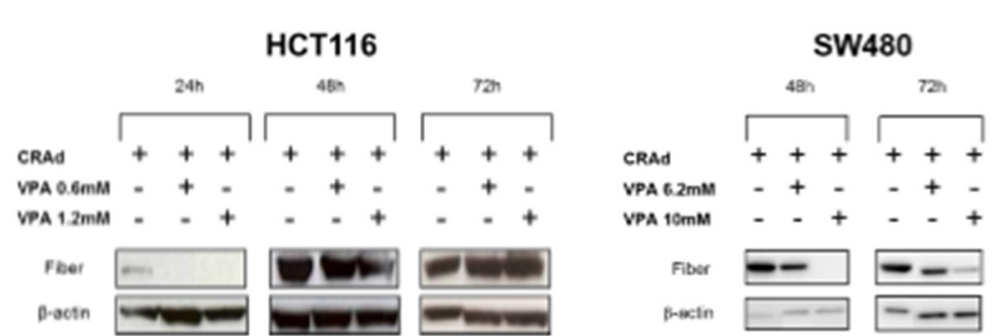

D

HT29

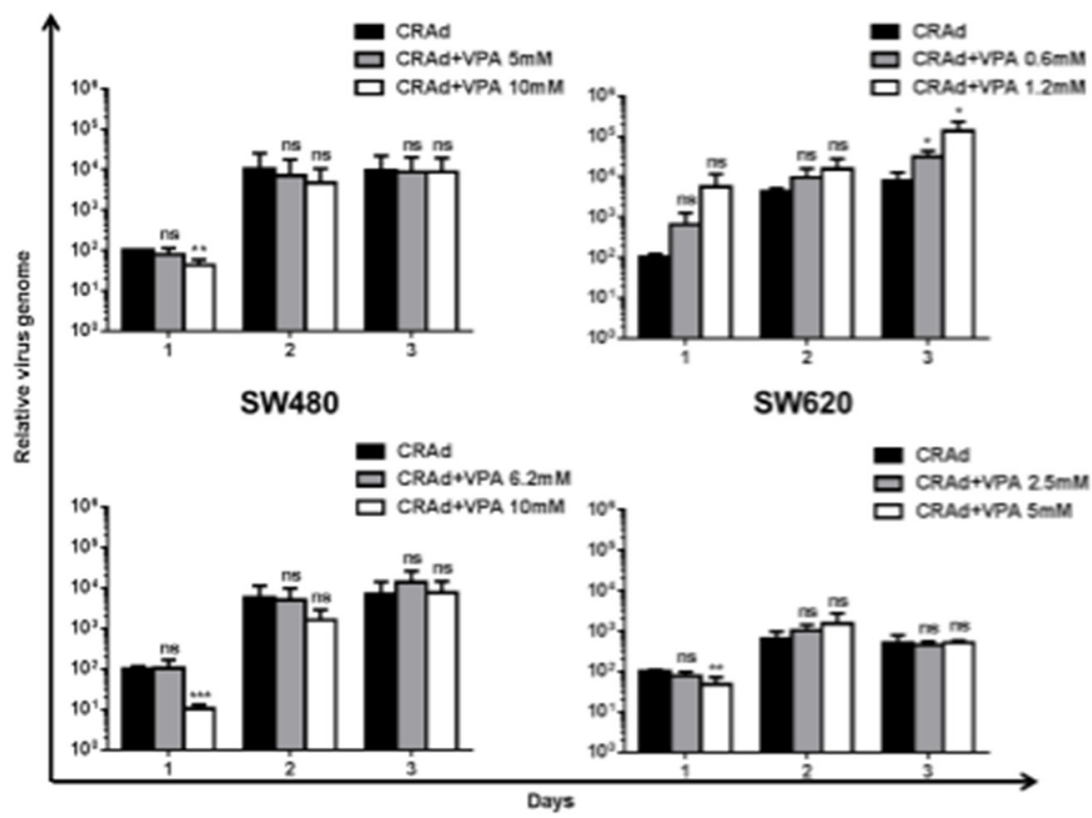

Figure 3: Effect of VPA on CRAd production in CRC cell lines. Colon carcinoma cells (HT29, HCT116, SW480 and SW620) were treated with CRAd (MOI $15.6 \mathrm{vp} /$ cell) with or without VPA (IC25 and IC50) for different times. (A) Viral production was measured at different time points post infection and expressed as TCID50/ml. Means + SD of 3 to 4 experiments; differences not significant. Expression of E1A early Ad proteins (B) and of the fiber late Ad protein (C) was detected by western blot. (D) Cell-associated viral DNA measured by quantitative PCR is expressed relative to level of viral DNA at day 1 post infection in control-treated infected cells. Means + SD of 2-3 experiments; ns, non significant; ${ }^{*} P<0.05 ;{ }^{* *} P<0.01 ;{ }^{* * *} P<0.001$. 
only infection. Besides cell cycle analysis, cell size and nuclear morphology were observed by phase-contrast microscopy following Wright-Giemsa staining. Figure 4C shows that some VPA-treated HT29 cells exhibited a small increase in cell and nuclei size compared to untreated cells. Cells infected with CRAd did not show significant change in nuclear morphology. In sharp contrast, HT29 cells exposed to CRAd and VPA co-treatment displayed an irregular nuclear morphology or multiple nuclei (Figure 4C, upper). Similar results were obtained with HCT116 cells submitted to CRAd plus VPA co-treatment (Figure 4C, lower). Cell size was investigated by forward side scatter measurement using flow cytometry. In both HT29 and HCT116 cell lines, CRAd infection triggered a significant increase in cell size (Supplementary Figure 6A). Interestingly, cells co-treated with a recombinant replication-defective Ad (Adßgal) did not display nuclear polyploidy or morphology changes (Supplementary Figure 6B). Using TO-PRO-3 and phalloidin staining to identify nuclei and cell contours respectively, the presence of several nuclei inside one plasma membrane in HT29 cells co-treated with CRAd and VPA was confirmed by confocal microscopy. Such modifications were not observed in infected cells in the absence of VPA (Figure 4D, Supplementary Figure 6B, Supplementary Figure 7A lower) and were restricted to cells expressing E1A, thereby linking this phenotype to virus infection in the presence of VPA. Similar observations were found from the analysis of the HCT116 cellular model (Supplementary Figure 7A). Taken as a whole these results demonstrate that co-treatment with CRAd and VPA triggers cell polyploidy with an increase in nuclei numbers.

\section{Co-treating cells with CRAd and VPA triggers strong DNA damage and is associated with inhibition of DNA repair proteins}

The increase in polyploidy following CRAd and VPA co-treatment prompted us to examine whether this phenotype could result from a higher incidence of DNA damage. As observed previously by others, VPA [27] and adenovirus [28] independently induce H2AX phosphorylation (Figure 5), a hallmark of DNA double strand breaks (DSB). Figure 5A shows that the co-treatment of HT29, HCT116 and SW480 cells with CRAd and VPA led to a higher $\gamma \mathrm{H} 2 \mathrm{AX}$ level compared to cells treated with either CRAd or VPA alone. This increase was detected 2 days after treatment and was even more pronounced after 3 days. In contrast, induction of $\gamma \mathrm{H} 2 \mathrm{AX}$ was not found following HT29 co-treatment with replication-deficient Ad $\beta$ gal and VPA (Supplementary Figure 7B), thereby suggesting that Ad replication is required for this phenomenon. Confocal microscopy studies confirmed that after 3 days, the combination of CRAd and VPA but not Ad $\beta$ Gal and VPA led to a significant increased percentage of $\gamma \mathrm{H} 2 \mathrm{AX}$-positive (77.0
$+7.0 \%)$ cells compared to CRAd-infected $(48.8+7,9 \%)$ or VPA-treated $(5 \mathrm{mM})$ non-infected cells $(24.3+3.0 \%)$ (Figure 5B). In addition, co-localization of $\gamma \mathrm{H} 2 \mathrm{AX}$ and DNA-binding protein (DBP), a protein expressed during viral replication demonstrated that the highest level of $\gamma \mathrm{H} 2 \mathrm{AX}$ at day 1 was induced in infected (DBP-positive) cells only upon VPA treatment (Figure 5C).

To better understand the molecular mechanisms at the origin of the strong $\mathrm{H} 2 \mathrm{AX}$ phosphorylation triggered by CRAd and VPA co-treatment, we assessed the expression of different DNA repair proteins by western blot. First, we investigated the expression of the members of Mre11-Rad50-Nbs1 (MRN) complex, a DSB sensor that is required for DNA repair by recombination. Figure 5D showed that CRAd led to a reduction of $\operatorname{Rad} 50$ at day 3 in both HT29 and SW480 cell lines, a reduction of Mre11 at day 3 in SW480 cells but has no activity on Nbs1 in both cell lines. VPA led to a strong reduction of Nbs1 and Mre11 levels in SW480 as soon as day 2 post-treatment but has no influence on levels of these proteins in HT29 (Figure 5D and data not shown). We also investigated whether the levels of proteins belonging to non-homologous end joigning (NHEJ) or homologous recombination (HR) DNA repair pathways could be modified by CRAd, VPA or both. Interestingly, after 3 days of infection with CRAd but not after treatment with VPA alone, both HT29 and SW480 displayed a reduced level of ligase IV, a key enzyme of the NHEJ process (Supplementary Figure 8). In addition, VPA but not CRAd triggered a reduction of Rad51, a key enzyme of the HR process, this reduction being more prominent in SW480 cells (Figure 5). These results demonstrate that CRAd and VPA independently down-regulate several key proteins of DNA repairs pathways. The down-regulation of several proteins observed in SW480 could explain the synergistic effect of the combination on the survival of this cell line (Supplementary Figure 1).

Since HDACi are potent reactive oxygen species (ROS) inducers $[29,30]$ and ROS could mediate DNA damage, we measured the level of ROS production in HT29 cells treated with CRAd, VPA and both using a fluorescent probe. The results indicated that the combined treatment elicits a strong production of ROS compared to single treatments (Supplementary Figure 7C). Altogether, these results suggest that the production of ROS could be at the origin of the increase of $\gamma \mathrm{H} 2 \mathrm{AX}$.

\section{Co-treatment with CRAd and VPA reduces tumor growth}

Having characterized the effects of the combined treatment with CRAd and VPA on CRC cell lines in vitro, we evaluated its therapeutic potential using nude mice bearing HT29 xenografts. First, we determined that a daily dose of VPA of $300 \mathrm{mg} / \mathrm{kg}$ led to a slight reduction of tumor growth, even if not statistically significant (Supplementary 

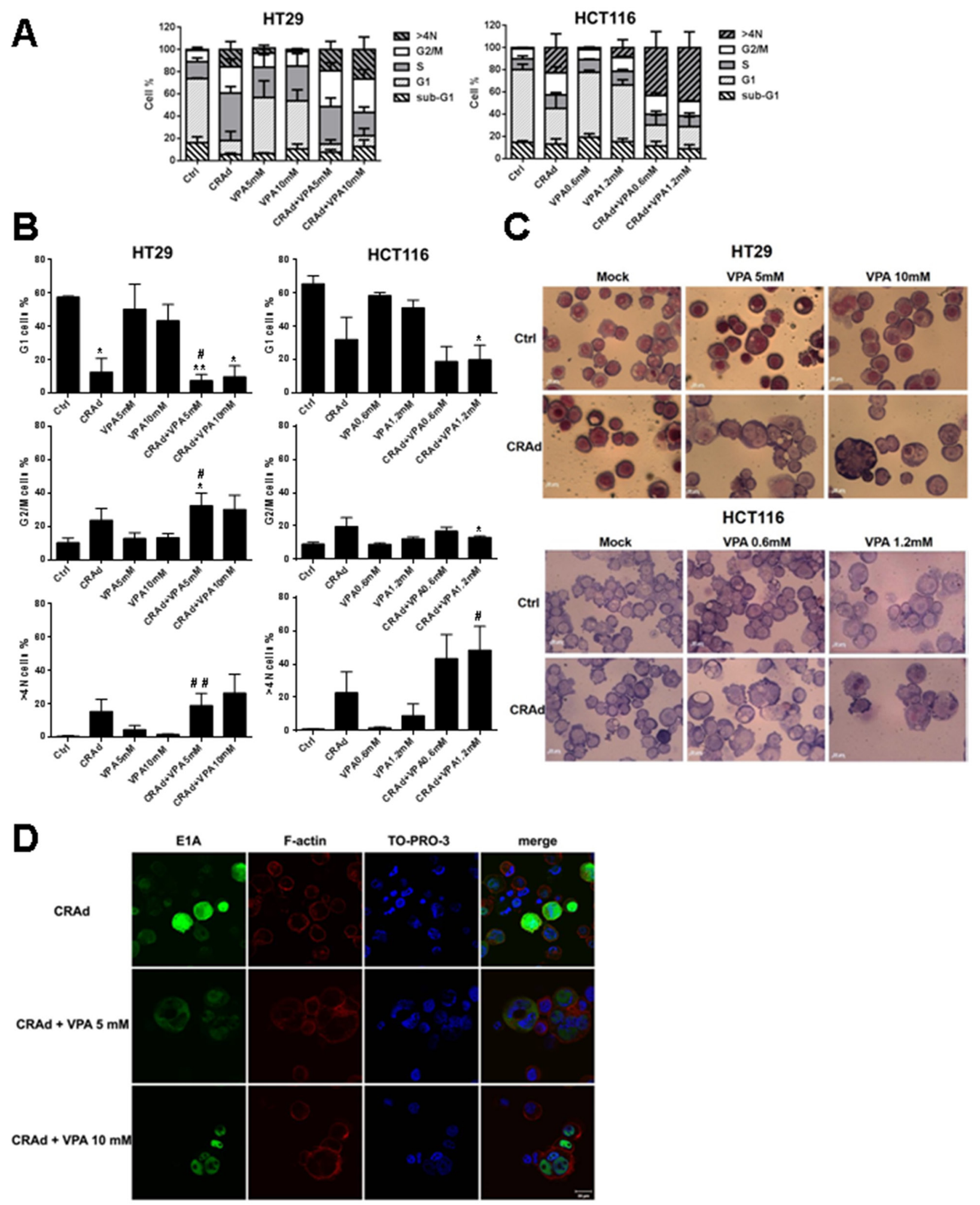

Figure 4: Modification of cell cycle and cell nuclei number after CRC cell line treatment with CRAd and VPA. CRC cell lines (HT29, HCT116, SW480, SW620) were untreated (Ctrl) or treated with CRAd (MOI 15.6 vp /cell), VPA (IC25 and IC50), or both. (A) Proportion of cells in the different phases of the cell cycle determined by flow cytometry at day 3. (B) Similar results as in A displayed to show statistical differences. Means + SEM of 3 experiments; ns, non significant; ${ }^{*} P<0.05,{ }^{* *} P<0.01$, ${ }^{* * *} P<0.001$ relative to Ctrl; ${ }^{\#} P<0.05$ and ${ }^{\#} P<0.01$ relative to CRAd. (C) Cell size and nuclei observed by phase contrast microscopy performed on cells attached via cytospin and stained with Wright-Giemsa at day 3 (scale bar, $20 \mu \mathrm{m}$ ). (D) Co-localization of E1A expression and nuclei assessed by confocal microscopy at day 2 in HT29 cells. F-actin was labelled with phalloidin and nuclei with TO-PRO-3; merge is shown (scale bar, $20 \mu \mathrm{m})$. The results are representative of two experiments. 

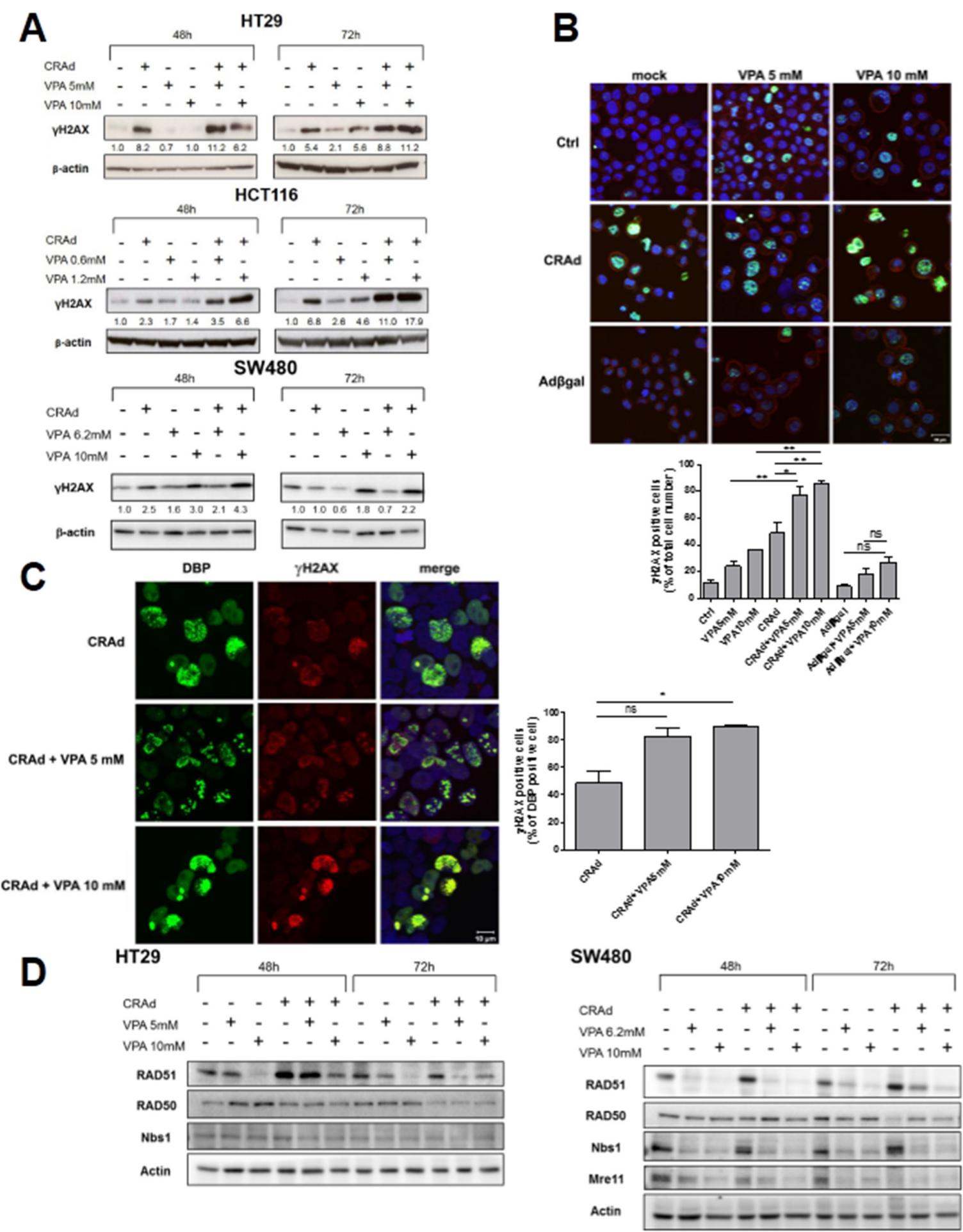

Figure 5: $\gamma \mathrm{H} 2 \mathrm{AX}$ induction and inhibition of DNA repair proteins after co-treatment of CRC cell lines with CRAd and VPA. CRC cell lines were untreated or treated with CRAd (A, B, C) or replication-deficient Adßgal (B) (MOI 15.6vp/cell), VPA (IC25 and IC50), or both. (A) At the indicated time, phosphorylation of $\mathrm{H} 2 \mathrm{AX}(\gamma \mathrm{H} 2 \mathrm{AX})$ was measured by western blot. The numbers indicate the level of $\gamma \mathrm{H} 2 \mathrm{AX}$ relative to untreated cells. (B) Upper, Expression of $\gamma \mathrm{H} 2 \mathrm{AX}$ (green) after 3 days in HT2 9 cells assessed by confocal microscopy. Actin cytoskeleton and nuclei were respectively stained with phalloidin and TO-PRO-3 (scale bar, $20 \mu \mathrm{m}$ ). Lower, Percentage of $\gamma \mathrm{H} 2 \mathrm{AX}$-positive cells. Means $+\mathrm{SD} ;{ }^{*} P<0.05$ and ${ }^{* *} P<0.01$. (C) Left, co-localization after $24 \mathrm{~h}$ in HT29 of adenovirus early DNA binding protein (DBP) (left panel, green) and $\gamma \mathrm{H} 2 \mathrm{AX}$ protein (middle panel, red) is shown in merge with TO-PRO-3 stained nuclei (right panel; scale bar, $10 \mu \mathrm{m}$ ). Rigth, Percentage of $\gamma \mathrm{H} 2 \mathrm{AX}$-positive cells among DBP-positive cells. Means $+\mathrm{SD} ;{ }^{*} P<0.05$. The results are representative of two experiments. TO-PRO-3 is represented arbitrary in blue. (D) Expression of DNA repair proteins at the indicated time points was measured by western blot. 
Figure 9). This dose was used in subsequent experiments to assess the ability of VPA to modify tumor growth when combined with CRAd. Of note, this dose corresponds after extrapolation based on body surface area [31] to the human equivalent dose of $24.3 \mathrm{mg} / \mathrm{kg}$ far below the maximal tolerated dose in humans of $60 \mathrm{mg} / \mathrm{kg} /$ day [32]. Mice were injected subcutaneously with HT29 cells, then after 12 days were injected intraperitoneally with PBS or VPA and intratumorally with either CRAd, a non-replicative virus (AdCO1), or PBS. Compared to VPA- and CRAd-injected mice, mice injected with CRAd and VPA displayed a significant reduction of tumor growth $(\mathrm{P}<0.01$ and $\mathrm{P}<0.05$, respectively). Most interestingly, mice injected with CRAd and VPA displayed significantly reduced tumors compared to mice treated with a replication-deficient AdCO1 and VPA (Figure 6A, $\mathrm{P}<0.01)$. This effect is associated with an increase in the necrotic areas in tumors retrieved from CRAd-plus-VPAinjected animals compared to CRAd-only injected animals (Figure 6B). Of note, this combined treatment was well tolerated since mice did not exhibit any significant weight loss (data not shown).

In order to better understand the significant antitumor efficacy observed between CRAd-plus-VPA versus CRAd-only injected mice, we examined the level of viral protein expression and viral replication in both groups. After 10 days of treatment, expression of viral hexon protein assessed in tumor sections by immunohistochemistry was comparable in both groups (Figure 6C). In addition, no difference was observed in viral production as documented by the measurement of viral genome (Figure 6D) and infectious particles (data not shown) by quantitative PCR and TCID50 assays, respectively. Altogether, our results indicate that combining CRAd with VPA led to a strong antitumor effect that is not associated with a better viral replication.

\section{DISCUSSION}

Oncolytic Ads used as a monotherapy do not replicate sufficiently in the tumors to have a significant therapeutic effect. Therefore, combining oncolytic Ads with other treatments is mandatory to achieve their full potential. In the present study, using different CRC cell lines, we demonstrated that combining CRAd with the HDACi VPA led to a poorer cancer cell survival compared to CRAd or VPA alone, both in vitro (Figures 1 and 2) and in vivo (Figure 6). Interestingly, such an effect was not found with the combination of a replication-deficient Ad and VPA. In addition, this effect was not observed with cell lines of renal or prostatic origin that are known to express low levels of CAR receptor [33, 34], thus suggesting it was linked to the efficient CRC cell line transduction by CRAd.

Other teams have investigated the potential of a combined treatment with an oncolytic Ad and HDACi with some discrepancies in the results. Thus, several teams reported an increased viral replication in different types of tumors due to a HDACi-mediated upregulation of CAR expression and better virus entry [35-38]. In contrast, one study reported that VPA inhibit adenovirus replication in both prostatic and colon carcinomas but experiments were conducted using a wild-type and not an oncolytic Ad [39]. Finally, a recent study reported no modification of CRAd replication after glioma cell treatment with VPA [40].

Taking into account these studies, we first measured viral replication and viral protein expression in different CRC cell lines to get insight into the therapeutic effect of the co-treatment with CRAd and VPA. Whereas a reduction in the level of viral genome and late protein (fiber) production was observed at day 1 post-infection in cells treated with VPA, viral particle production at later time points remained unaffected (Figure 3). In addition, the levels of viral replication and late protein (hexon) expression were comparable in CRAd-injected tumors of mice treated with or without VPA (Figure 6). Taken as a whole, the therapeutic effect mediated by the combination of CRAd and VPA does not stem from a better viral replication.

The efficacy of the combination of CRAd and VPA was shown using both MTT and crystal violet assays (Figure 1). Since the two methods do not discriminate between cell death and reduction in cell proliferation, the effect of the co-treatment on CRC cell lines was investigated using more accurate methods. First, for all cell lines, we reported a reduction of cell number after 3 days of treatment with VPA or CRAd that was even more pronounced in co-treated cells (Supplementary Figure 3). The VPA-induced reduction of cell number was already reported for different types of tumor cells, including a CRC cell line [41]. The fact that an increase in p21 expression was observed following cell treatment with VPA or CRAd and VPA in HT29, HCT116 and SW480 cells provides a molecular basis to the inhibition of proliferation observed in these cells co-treated with VPA alone or combined with CRAd. In addition, since p21 was previously shown to bind pro-caspase- 3 and inhibit its cleavage [42], the expression of p21 may account for the lack of apoptosis in these cell lines. Of note, no senescence associated- $\beta$-galactosidase (SA $\beta$ Gal) activity was found following CRAd and VPA cotreatment ruling out that the inhibition of proliferation occurs through a p21-mediated process of senescence [43]. Second, with the exception of SW620, a slight increase in cell death was found in cells co-treated with CRAd and VPA, as documented by LDH release. No increases were found in the subG1 population (Figure 4) and Parp-1 or caspase-3 cleavage (Supplementary Figure 5B), thereby excluding a massive apoptotic cell death. Besides p21 upregulation, the absence of apoptosis in our cell lines might be due to the mutated status of $A P C$ leading to increased survivin level and resistance to apoptosis as described previously following treatment with VPA of different CRC cell lines [44]. 
During our analysis of the cell cycle, we observed the emergence of a $>4 \mathrm{~N}$ population in CRAd-infected cells as reported by others $[45,46]$. In contrast, VPA was unable to trigger significant occurrence of the $>4 \mathrm{~N}$ population in accordance with its capacity to inhibit cell proliferation [41]. Interestingly, cells co-treated with CRAd and VPA displayed an increase in the $>4 \mathrm{~N}$ population (Figure 4B) as well as a larger size and a higher nuclear content (Figure 4C). Such an increase in $>4 \mathrm{~N}$ population was also documented by others after cell treatment with oncolytic Ad and an aurora B inhibitor [45] or paclitaxel, a drug that stabilizes microtubules [47]. In our studies, using confocal

\section{A}
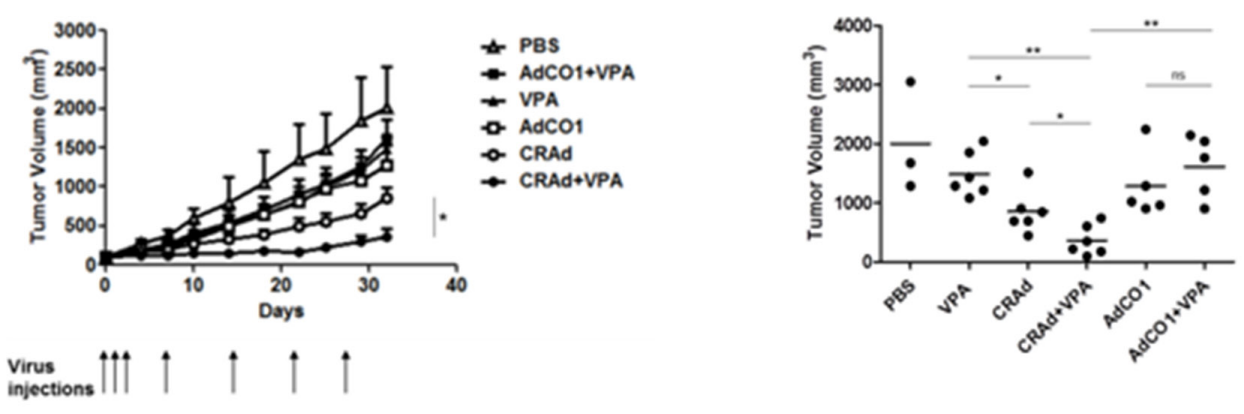

B
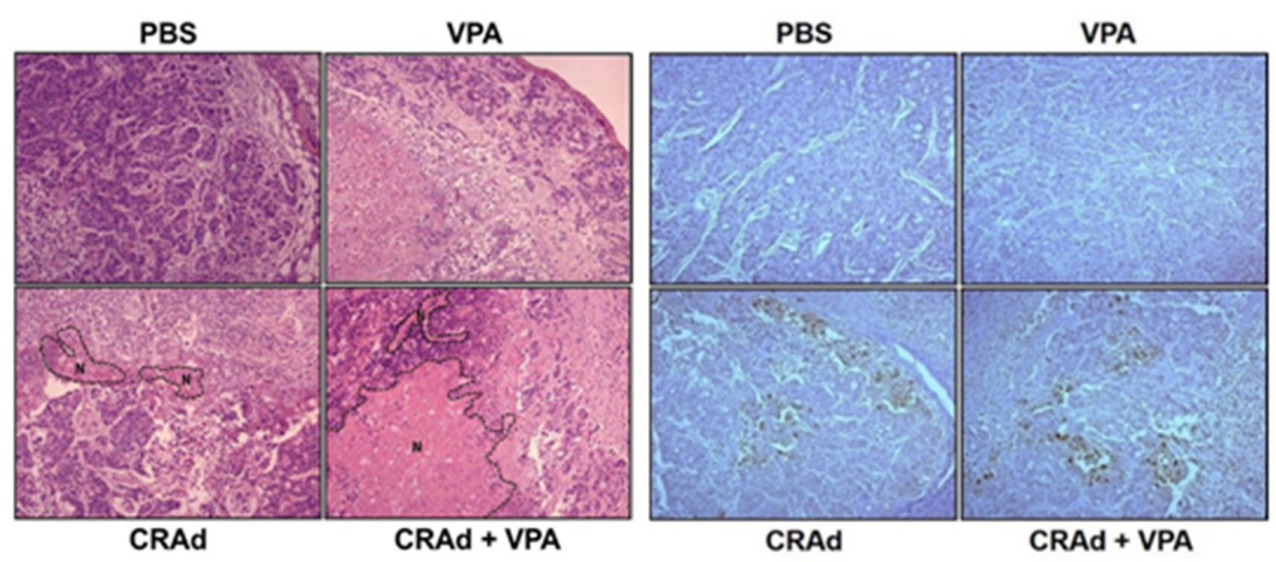

D

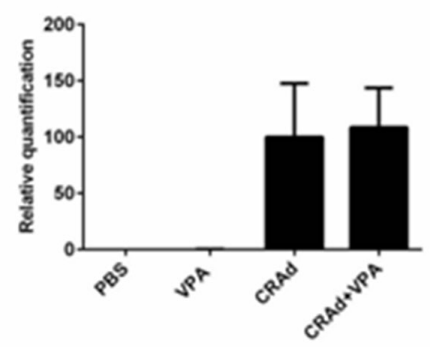

Figure 6: Reduction of tumor growth following the treatment of colon carcinoma tumors with CRAd and VPA. Mice bearing HT29-derived xenografts were injected intraperitoneally with daily injection of VPA ( $300 \mathrm{mg} / \mathrm{kg})$ or PBS and at the indicated time points (arrows) injected intratumorally with virus (CRAd or non-replicative AdCO1) or PBS. (A) Kinetics of tumor growth showing means + SEM (left) and tumor volumes at day 32 with dots and bars representing results of individual mice $(n=3$ to 6$)$ and means, respectively (right). At day 10 of the treatment (B) HES staining of tumor sections (magnification $\times 100$ ) showing areas of necrosis $(\mathrm{N})$ surrounded by dotted lines, (C) detection of hexon protein in tumor sections by immuno-histochemistry (magnification $\times 100$ ), and (D) measurement of viral genome level by Q-PCR. ${ }^{*} P<0.05$ and ${ }^{* *} P<0.01$. 
analyses, we linked this $>4 \mathrm{~N}$ population to the occurrence of polyploidy in CRAd-infected cells only after treatment with VPA. This polyploidy in oncolytic Ad-infected cells is more likely the consequence of VPA-mediated inhibition of key steps in cell division, as observed with other chemotherapies [45, 47].

VPA and CRAd are known to inhibit DNA repair independently. Indeed, VPA is able to trigger, in a dosedependent manner, the phosphorylation of histone H2AX, a hallmark of DSBs [27]. Recently, VPA was shown to block DSB repair through an autophagy-dependent downregulation of CtIP (Sae2) and Exo1, both of which are involved in sensing DSB [48]. Adenovirus infection induces $\gamma \mathrm{H} 2 \mathrm{AX}$ [28] and targets different proteins involved in DNA repair (MRE11, ligase IV and DNA-PK), leading to their inactivation/relocalization/degradation [49, 50]. Our results confirmed strong H2AX phosphorylation induced by CRAd and to a minor extent by VPA, but also highlighted a stronger $\gamma \mathrm{H} 2 \mathrm{AX}$ level following cell co-treatment with CRAd and VPA (Figure 5A and 5B). Interestingly, such an increase in $\gamma \mathrm{H} 2 \mathrm{AX}$ was not found following cell co-treatment with a replication-deficient $\mathrm{Ad}$ and VPA (Supplementary Figure 7B), suggesting a role of viral replication (or E1A expression) in accordance with a previous report [28]. This observation together with the lack of polyploidy observed in VPA-treated cells infected with a replication-deficient Ad (Supplementary Figure 6B) suggest that an increased level of DSB in cells co-treated with CRAd and VPA underlies the genetic instability and increased polyploidy. This polyploidy could be responsible for the inhibition of cell proliferation as observed by others [51].

To understand the origin of DSB, we analysed the influence of CRAd and VPA on the expression of DNA repair proteins in two $\mathrm{CRC}$ cell lines. Interestingly, CRAd alone reduces the level of Rad50 in both HT29 and SW480 cell lines and inhibits Mre11 protein level in SW480 (Figure 5D). Our results are in accordance with a previous study showing degradation of Rad50 and Mre11 by Ad early proteins E1B55kDa and E4orf6 [49]. However, in contrast to this study, Nbs1 level in our cell model was not modified by CRAd. In addition, we also observed that CRAd-infected cells display a reduced level of ligase IV, a critical component of NHEJ pathway (Supplementary Figure 8). This could be linked to a E1B55kDa and E4orf6-mediated degradation process as described previously [52]. Besides CRAd-induced downregulation of DNA repair proteins, we reported that VPA alone led to a dramatic reduction of Rad51 in both HT29 and SW480 and to a decrease of Nbs1 and Mre11 levels in SW480 cells but not in HT29 cells (Figure 5D and data not shown). Modulation of protein levels by VPA was reported earlier for $\operatorname{Rad} 51[53,54]$ but neither for $\mathrm{Nbs} 1$ nor for Mre11. Thus, CRAd and VPA act independently to reduce different proteins of DNA repair. They could on also act together to modulate Mre11 as suggested by lower Mre11 levels in CRAd and VPA treated cells compared to single treatments (Figure 5D). As a result, the reduction of Mre11 levels could impair the correct telomere maintenance leading to their fusion [55-58] and the observed polyploidy (Figure 4). Of note, this polyploidy is not related to microsatellite stability (MSS) or instability (MSI) phenotype. Indeed, HT29, SW480 and SW620 displaying a MSS phenotype present a polyploidy comparable to HCT116 having a MSI phenotype [59]. Finally, our observation of a stronger ROS production after CRAd and VPA cotreatment (Supplementary Figure 7C) suggests that ROS by their ability to trigger DNA damage may participate to the strong induction of $\gamma \mathrm{H} 2 \mathrm{AX}$.

In conclusion, our results demonstrate that the combination of CRAd and VPA leads to a strong reduction of colon carcinoma growth both in vitro and in vivo. This effect requires CRAd replication since such effect was not found both in vitro and in vivo using a replication-deficient Ad and VPA. The inhibition of cell proliferation and the induction of cell death are the main mechanisms of action of CRAd-VPA combination. In our in vivo experiments, CRAd and VPA were injected intraperitonally and intratumorally, respectively. Other ways of administration of CRAd such as direct injection into orthotopic colon tumors or intravenous injection should help to ascertain the potential of CRAd-VPA combined therapy for the cure of colon carcinomas. The development of such cotreatment should be facilitated by the feedback from previous clinical trials targeting cancer and testing VPA or CRAd.

\section{MATERIALS AND METHODS}

\section{Cell lines}

Colon-(HT29, HCT116, SW480 and SW620), prostatic-(LNCaP) and renal (786-O)-derived carcinomas were obtained from American Type Culture Collection (ATCC) and maintained in media recommended by ATCC. Of note, whereas HT29, SW480 and SW620 present a microsatellite stability (MSS) phenotype, HCT116 displays a microsatellite instability (MSI) phenotype [59].

\section{Adenovirus}

Adßgal, a lacZ recombinant Ad with E1 and E3 regions deleted [60], and AdCO1, which expresses no transgene [61] were used in these studies. AdE1 $\Delta 24$ was derived from $A d \beta g a l$ using the following procedure: First, the E1 $\Delta 24$ gene from pXC1- $\Delta 24$ carrying a 24 bp deletion removing the pRb-binding CR2 domain of E1A (kindly provided by Dr VW van Beusechem) was cloned into pXL3048. Recombination in E. coli of pXL3048-E1 $\Delta 24$ and the Adßgal genome enabled us to obtain the AdE1 $\Delta 24$ genome. All viruses were produced and purified as 
described previously [62]. Titers were measured by spectrophotometry $\left(1 \mathrm{OD}_{260}=1.1 \times 10^{12} \mathrm{vp} / \mathrm{ml}\right)$.

\section{Cell viability and Chou-Talalay analysis}

Cells $\left(10^{4}\right.$ to $\left.5 \times 10^{4}\right)$ were plated on 96 -well plates and treated with different multiplicity of infection (MOI) of AdE1 $\triangle 24$ (referred below as CRAd) and/or different doses of VPA (Sigma-Aldrich), as defined in Supplementary Table 1 . After 3 days, the medium was removed and cells were stained with crystal violet $0.2 \%$ for $15 \mathrm{~min}$. Then, plates were washed and dried before performing macroscopic observation. Alternatively, cell viability was measured at different time points using an MTT assay. The results (mean $\pm \mathrm{SD}$ ) were expressed relative to VPA-matched non-infected cells or relative to cell control at day 1 for the kinetic experiment.

For Chou-Talalay analysis, fixed ratios of the IC50 value of VPA and/or CRAd where used to treat the cells either individually or in combination. Combined dose-response curves were fitted to Chou-Talalay lines [25]. Combination indexes (CI) were determined using CompuSyn software (ComboSyn Inc., Paramus, NJ). CI $<1.2,0.8<\mathrm{CI}<1.2$ and $\mathrm{CI}>1.2$ indicate synergistic, additive and antagonistic interactions, respectively.

\section{Cell proliferation and death}

For carboxyfluorescein succinimidyl ester (CFSE) staining, cells were harvested and loaded with $5 \mu \mathrm{M}$ CFSE for $10 \mathrm{~min}$ at room temperature. After washing with PBS, cells $\left(5 \times 10^{5}\right)$ were seeded in 6-well plates and exposed the next day to different conditions. The proliferation index corresponds to the ratio of CFSE mean fluorescence intensity of cells before treatment to mean fluorescence intensity after 3 days of treatment. The proliferation index was expressed relative to the control-treated cells.

For the specific measurement of cell death, cells $\left(5 \times 10^{5}\right)$ were plated on 6-well plates and treated as described above. Then, supernatants were collected and lactate dehydrogenase (LDH) activity was measured using in vitro toxicology assay kit (Sigma Aldrich). The results were expressed relative to total LDH level obtained with cells treated with identical conditions and permeabilized with triton $0.1 \%$.

\section{ROS production}

Cells seeded in 6-well plates, $\left(5 \times 10^{5}\right.$ cells/well $)$, were treated with AdE1 $\Delta 24$ (MOI $15.6 \mathrm{vp} / \mathrm{cell}$ ), with or without VPA (low and high doses). Cells were harvested, washed with PBS and incubated with Dihydroethidium $(0.5 \mu \mathrm{M})$. After $20 \mathrm{~min}$, cells were analyzed by cytometry using FACscan cytometer (Beckson Dickinson) and CellQuest software (Beckton Dickinson).

\section{In vitro and in vivo virus production}

Cells seeded in 6-well plates, $\left(5 \times 10^{5}\right.$ cells/well $)$ were infected with AdE1 $\Delta 24$ (MOI 15.6vp/cell), with or without VPA, in adequate medium supplemented with $2 \%$ FBS. After one hour, $3 \mathrm{ml}$ of growth medium with or without VPA was added. Then, at different time points post-infection (p.i.), cells were scrapped and, cells and medium were harvested. After freeze-thaw cycles, the number of infectious particles was determined by TCID50 assay on 293A cells (Invitrogen). The results are expressed as TCID50/ml.

For quantification of the viral genome, cells were harvested and, after centrifugation and washing, total DNA was extracted using Nucleospin Tissue kit according to the manufacturer instructions (Macherey-Nagel, Hoerdt, France). The viral genome was assessed using primers for the viral gene hexon: forward (5'-CTTACCCCCAACGAGTTTGA-3') and reverse (5'GGAGTACATGCGGTCCTTGT-3'). As an internal positive control, eukaryotic 18S rRNA was amplified using the following primers: forward (5'-CGTTCAGCCACCCGAGAT-3') and reverse (5'-AACCTGCGGAAGGATCATTA-3'). Amplification was monitored in duplicate on a StepOne Real-Time PCR system (Applied Biosystems, Perkin-Elmer) using SYBR Green reagent (Applied Biosystems, Perkin-Elmer) according to the manufacturer instructions, under the following conditions: $2 \mathrm{~min}$ incubation at $50^{\circ} \mathrm{C}, 10 \mathrm{~min}$ at $95^{\circ} \mathrm{C}$, followed by 40 cycles of repeated incubations at $95 \mathrm{C}^{\circ}$ for $15 \mathrm{~s}$ and $60^{\circ} \mathrm{C}$ for $1 \mathrm{~min}$. Viral genome levels in cells were analyzed by the comparative $\Delta \Delta \mathrm{Ct}$ method and expressed relative to the Ad-genome level measured in cells infected with AdE1 $\Delta 24$ alone.

\section{Western blot}

Cells seeded in 6-well plates, $\left(5 \times 10^{5}\right.$ cells/well $)$, were treated with AdE1 $\triangle 24$ (MOI $15.6 \mathrm{vp} / \mathrm{cell})$, with or without VPA (low and high doses). At indicated time points post infection (p.i.), cells were harvested and protein extracts were prepared in RIPA buffer $(10 \mathrm{mM}$ Tris base $\mathrm{pH}$ $8.8, \mathrm{NaCl} 150 \mathrm{mM}$, EDTA $1 \mathrm{mM}$, NP-40 1\%, deoxycholic acid $1 \%$ ) supplemented with a mini EDTA-free protease inhibitor cocktail tablet (Roche). Protein extracts ( 25 or 40 $\mu \mathrm{g})$ were run in NuPAGE (Invitrogen, France), 9\% SDSPAGE gels or 3-8\% Tris Acetate precast gels (Biorad, Hercules, CA, USA), transferred onto a nitrocellulose membrane, and probed with anti-fiber (AB4 clone 4D2, Thermoscientific), anti-E1A (sc-430, Santa-Cruz), antiphospho-histone H2AX (anti- $\gamma \mathrm{H} 2 \mathrm{AX}$ (ser 139), clone JBW301, Millipore), anti-p21 (OP-64, Calbiochem or Santa Cruz Biotechnology, Dallas TX, USA), anti-RAD51 (Merck Millipore, Darmstadt, Germany), anti-Ligase IV (Genetex, Taiwan, R.O.C), anti-Nbs1, anti-DNA-PK and 
anti-Ku70 (Thermofisher scientific, Waltham, MA, USA), anti-RAD50 and anti-Vinculin (Abcam, Cambridge UK), anti-p21 (Santa Cruz biotechnology), anti- $\alpha$ Tubulin and anti-ßactin antibodies (Clone AC-15, Sigma-Aldrich), followed by HRP-conjugated secondary antibody. When required, protein extracts were sonicated before separation on PAGE. The western blot results were quantified by Image-J software and expressed as arbitrary units relative to untreated cells. Immunoreactivity was visualized using an enhanced chemoluminescence detection kit (ECL, Pierce).

\section{Cell cycle}

Cells seeded in 6 -well plates, $\left(5 \times 10^{5}\right.$ cells/well $)$, were untreated or treated with CRAd (MOI $15.6 \mathrm{vp} / \mathrm{cell}$ ) with or without VPA (low and high dose) for 72 hours. Then, cells were harvested, centrifuged, and resuspended in sodium citrate buffer containing Triton X-100 0.1\%, RNAse $100 \mu \mathrm{g} / \mathrm{ml}$, and propidium iodide $50 \mu \mathrm{g} / \mathrm{ml}$. Cell cycle distribution was determined by flow cytometry analysis performed on Facscalibur (Beckman).

\section{Morphologic evaluation with Wright-Giemsa dyeing}

Cells seeded in 6-well plates, $\left(5 \times 10^{5}\right.$ cells/well $)$, were untreated or treated with virus (CRAd or Adßgal, MOI $15.6 \mathrm{vp} /$ cell) with or without VPA (low and high dose). After $72 \mathrm{~h}$, cells were harvested, attached to slides via cytospin, fixed with Wright stain (WS16, Sigma) and stained for 15 minutes in Giemsa solution (GS500, Sigma). After washing, dry slides were mounted with a coverslip. Cells and nuclei observations were performed using phase-contrast microscopy.

\section{Confocal microscopy}

Cells seeded in 6-well plates, $\left(5 \times 10^{5}\right.$ cells/well $)$, were untreated or treated with CRAd or Adßgal (MOI $15.6 \mathrm{vp} /$ cell) with or without VPA (low and high dose). After two days, adherent cells were detached with TrypLE ${ }^{\mathrm{TM}}$ Express (Invitrogen) and collected together with non-adherent cells and attached on slides by using cytospin centrifuge, $500 \mathrm{rpm}$ during $5 \mathrm{~min}$. Cells grown on a cover glass were washed with PBS and fixed with $2 \%$ paraformaldehyde for $12 \mathrm{~min}$. After permeabilization with Triton X-100 0.5\% for $10 \mathrm{~min}$, cells were blocked with PBS containing 3\% BSA for $30 \mathrm{~min}$. Samples were exposed overnight to primary antibodies (anti-E1A sc-430; anti-DBP, a gift from Dr D.F. Klessig; anti- $\gamma \mathrm{H} 2 \mathrm{AX}$ ) in PBS-BSA followed by Alexa Fluor-conjugated secondary antibody labeling for $4 \mathrm{~h}$. Nuclei were contrast stained with TO-PRO-3 and Alexa Fluor 555-labeled phalloidin (Sigma) was used to selectively label F-actin. Slides were mounted in mounting media and observed using the Zeiss LSM 510 confocal microscope.

\section{In vivo experiments}

For in vivo studies, all animal experiments were approved by the IGR Institutional Animal Care and Use Committee. HT29 cells ( $10^{7}$ cells) in $100 \mu$ of PBS were injected subcutaneously into athymic NU/NU female mice housed at the Institut Gustave Roussy. When tumors reached 70-100 $\mathrm{mm}^{3}$, mice were injected intratumorally with virus (AdE1 $\triangle 24$ or AdCO1) or PBS for three consecutive days every week for 4 weeks. In parallel and beginning at day 4 , mice received intraperitoneal injections of VPA $(300 \mathrm{mg} / \mathrm{kg})$ or PBS in a volume of $200 \mu$ l five consecutive days per week until the end of the protocol. Tumor growth was measured twice per week and weight five days per week for 4 weeks. In some experiments, mice were sacrificed, tumors were harvested and total DNA was extracted using Nucleospin Tissue kit. Viral genome content was determined by real-time quantitative PCR as described above.

\section{Histology and immunohistology}

Tumors were excised, fixed in FineFix (Milestone), and embedded in paraffin. Sections $(4 \mu \mathrm{m})$ were stained with hematoxylin-eosin-safranin (HES). Hexon protein was detected using a polyclonal anti-adenovirus hexon protein (AB1056, Chemikon, CA) and a biotinylated rabbit anti-goat immunoglobulin antibody conjugated to streptavidin-horseradish peroxidase (DAKO, France); slides were counterstained with hematoxylin.

\section{Statistical analyses}

For in vitro experiments a two-tailed paired $\mathrm{t}$ test was conducted using Graphpad Prism. For in vivo experiments, a Mann-Whitney test, recommended for groups fewer than 30 mice, was conducted. Differences were considered significant when $P<0.05$.

\section{ACKNOWLEDGMENTS}

We are very grateful to all members of Gustave Roussy animal facility (Pre-clinical Evaluation Unit, PFEP) and to Imaging and Cytometry Platform (PFIC) for technical help. We thank Josiane Pierre for providing us with the CRC cell lines and Muriel David for helpful discussions. C.B. and N.R. received fellowships from the Ministère de la Recherche et de la Technologie. N.R. received an additional fellowship from University ParisSud. E.G. was supported by fellowships from the INCa and EDF. DM was supported by fellowship from the HRZZ and UKF. 


\section{CONFLICTS OF INTEREST}

The authors have no competing financial interests to declare.

\section{FINANCIAL SUPPORT}

This work was supported by grants to K.B. from the INCa (PIMRANIS project) and from EDF.

\section{REFERENCES}

1. Brenner H, Kloor M, Pox CP. Colorectal cancer. Lancet. 2014; 383: 1490-502. https://doi.org/10.1016/ S0140-6736(13)61649-9.

2. Yamamoto M, Curiel DT. Current issues and future directions of oncolytic adenoviruses. Mol Ther. 2010; 18: 243-50. https://doi.org/10.1038/mt.2009.266.

3. Kaufmann JK, Nettelbeck DM. Virus chimeras for gene therapy, vaccination, and oncolysis: adenoviruses and beyond. Trends Mol Med. 2012; 18: 365-76. https://doi. org/10.1016/j.molmed.2012.04.008.

4. Liu TC, Kirn D. Systemic efficacy with oncolytic virus therapeutics: clinical proof-of-concept and future directions. Cancer Res. 2007; 67: 429-32. https://doi. org/10.1158/0008-5472.CAN-06-2871.

5. Rogulski KR, Freytag SO, Zhang K, Gilbert JD, Paielli DL, Kim JH, Heise CC, Kirn DH. in vivo antitumor activity of ONYX-015 is influenced by 53 status and is augmented by radiotherapy. Cancer Res. 2000; 60: 1193-6.

6. Fueyo J, Gomez-Manzano C, Alemany R, Lee PS, McDonnell TJ, Mitlianga P, Shi YX, Levin VA, Yung WK, Kyritsis AP. A mutant oncolytic adenovirus targeting the $\mathrm{Rb}$ pathway produces anti-glioma effect in vivo. Oncogene. 2000; 19: 2-12. https://doi.org/10.1038/sj.onc.1203251.

7. Heise C, Hermiston T, Johnson L, Brooks G, SampsonJohannes A, Williams A, Hawkins L, Kirn D. An adenovirus E1A mutant that demonstrates potent and selective systemic anti-tumoral efficacy. Nat Med. 2000; 6: 1134-9. https://doi. org/10.1038/80474.

8. Hoffmann D. Restriction of adenoviral replication to the transcriptional intersection of two different promoters for colorectal and pancreatic cancer treatment. Mol Cancer Ther. 2006; 5: 374-81. https://doi.org/10.1158/1535-7163. MCT-05-0374.

9. Hamid O. Phase II trial of intravenous CI-1042 in patients with metastatic colorectal cancer. J Clin Oncol. 2003; 21: 1498-504. https://doi.org/10.1200/JCO.2003.09.114.

10. Au T, Thorne S, Korn WM, Sze D, Kirn D, Reid TR. Minimal hepatic toxicity of Onyx-015: spatial restriction of coxsackie-adenoviral receptor in normal liver. Cancer Gene Ther. 2007; 14: 139-50.

11. Kishimoto H, Urata Y, Tanaka N, Fujiwara T, Hoffman RM. Selective metastatic tumor labeling with green fluorescent protein and killing by systemic administration of telomerase-dependent adenoviruses. Mol Cancer Ther. 2009; 8: 3001-8. https://doi.org/10.1158/1535-7163. MCT-09-0556.

12. Parato KA, Senger D, Forsyth PA, Bell JC. Recent progress in the battle between oncolytic viruses and tumours. Nat Rev Cancer. 2005; 5: 965-76. https://doi.org/10.1038/ nrc1750.

13. Zhang Z, Zou W, Wang J, Gu J, Dang Y, Li B, Zhao L, Qian C, Qian Q, Liu X. Suppression of tumor growth by oncolytic adenovirus-mediated delivery of an antiangiogenic gene, Soluble Flt-1. Mol Ther. 2005; 11: 553-62. https://doi. org/10.1016/j.ymthe.2004.12.015.

14. Akbulut H, Zhang L, Tang Y, Deisseroth A. Cytotoxic effect of replication-competent adenoviral vectors carrying L-plastin promoter regulated E1A and cytosine deaminase genes in cancers of the breast, ovary and colon. Cancer Gene Ther. 2003; 10: 388-95. https://doi.org/10.1038/ sj.cgt.7700579.

15. Bressy C, Benihoud K. Association of oncolytic adenoviruses with chemotherapies: an overview and future directions. Biochem Pharmacol. 2014; 90: 97-106. https:// doi.org/10.1016/j.bcp.2014.05.003.

16. Heise C, Sampson-Johannes A, Williams A, McCormick F, Von Hoff DD, Kirn DH. ONYX-015, an E1B geneattenuated adenovirus, causes tumor-specific cytolysis and antitumoral efficacy that can be augmented by standard chemotherapeutic agents. Nat Med. 1997; 3: 639-45.

17. Homicsko K, Lukashev A, Iggo RD. RAD001 (everolimus) improves the efficacy of replicating adenoviruses that target colon cancer. Cancer Res. 2005; 65: 6882-90.

18. Sachs MD, Ramamurthy M, Poel HV, Wickham TJ, Lamfers M, Gerritsen W, Chowdhury W, Li Y, Schoenberg MP, Rodriguez R. Histone deacetylase inhibitors upregulate expression of the coxsackie adenovirus receptor (CAR) preferentially in bladder cancer cells. Cancer Gene Ther. 2004; 11: 477-86. https://doi.org/10.1038/sj.cgt.7700726.

19. Kothari V, Joshi G, Nama S, Somasundaram K, Mulherkar R. HDAC inhibitor valproic acid enhances tumor cell kill in adenovirus-HSVtk mediated suicide gene therapy in HNSCC xenograft mouse model. Int J Cancer. 2010; 126: 733-42. https://doi.org/10.1002/ijc.24700.

20. Mariadason JM. HDACs and HDAC inhibitors in colon cancer. Epigenetics. 2008; 3: 28-37.

21. Zhu P, Martin E, Mengwasser J, Schlag P, Janssen KP, Göttlicher M. Induction of HDAC2 expression upon loss of APC in colorectal tumorigenesis. Cancer Cell. 2004; 5: 455-63.

22. Marks PA, Xu WS. Histone deacetylase inhibitors: potential in cancer therapy. J Cell Biochem. 2009; 107: 600-8. https://doi.org/10.1002/jcb.22185.

23. Krämer $\mathrm{OH}$, Zhu $\mathrm{P}$, Ostendorff $\mathrm{HP}$, Golebiewski M, Tiefenbach J, Peters MA, Brill B, Groner B, Bach I, Heinzel T, Göttlicher M. The histone deacetylase inhibitor 
valproic acid selectively induces proteasomal degradation of HDAC2. EMBO J. 2003; 22: 3411-20.

24. Mologni L, Cleris L, Magistroni V, Piazza R, Boschelli F, Formelli F, Gambacorti-Passerini C. Valproic acid enhances bosutinib cytotoxicity in colon cancer cells. Int J Cancer. 2009; 124: 1990-6. https://doi.org/10.1002/ijc.24158.

25. Chou TC. Drug combination studies and their synergy quantification using the Chou-Talalay method. Cancer Res. 2010; 70: 440-6. https://doi.org/10.1158/0008-5472. CAN-09-1947.

26. Ravizza R, Gariboldi MB, Passarelli L, Monti E. Role of the p53/p21 system in the response of human colon carcinoma cells to doxorubicin. BMC Cancer. 2004; 4: 92. https://doi. org/10.1186/1471-2407-4-92.

27. Hubaux R, Vandermeers F, Crisanti C, Kapoor V, Burny A, Mascaux C, Albelda SM, Willems L. Preclinical evidence for a beneficial impact of valproate on the response of small cell lung cancer to first-line chemotherapy. Eur J Cancer. 2010; 46: 1724-34. https://doi.org/10.1016/j. ejca.2010.03.021.

28. Nichols GJ, Schaack J, Ornelles DA. Widespread phosphorylation of histone $\mathrm{H} 2 \mathrm{AX}$ by species $\mathrm{C}$ adenovirus infection requires viral DNA replication. J Virol. 2009; 83: 5987-98. https://doi.org/10.1128/JVI.00091-09.

29. Botrugno OA, Robert T, Vanoli F, Foiani M, Minucci S. Molecular pathways: old drugs define new pathways: nonhistone acetylation at the crossroads of the DNA damage response and autophagy. Clin Cancer Res. 2012; 18: 243642. https://doi.org/10.1158/1078-0432.CCR-11-0767.

30. Eot-Houllier G, Fulcrand G, Magnaghi-Jaulin L, Jaulin C. Histone deacetylase inhibitors and genomic instability. Cancer Lett. 2009; 274: 169-76. https://doi.org/10.1016/j. canlet.2008.06.005.

31. Reagan-Shaw S, Nihal M, Ahmad N. Dose translation from animal to human studies revisited. FASEB J. 2007; 22: 65961. https://doi.org/10.1096/fj.07-9574LSF.

32. Atmaca A, Al-Batran SE, Maurer A, Neumann A, Heinzel T, Hentsch B, Schwarz SE, Hövelmann S, Göttlicher M, Knuth A, Jäger E. Valproic acid (VPA) in patients with refractory advanced cancer: a dose escalating phase I clinical trial. Br J Cancer. 2007; 97: 177-82. https://doi.org/10.1038/ sj.bjc.6603851.

33. Haviv YS, Blackwell JL, Kanerva A, Nagi P, Krasnykh V, Dmitriev I, Wang M, Naito S, Lei X, Hemminki A, Carey D, Curiel DT. Adenoviral gene therapy for renal cancer requires retargeting to alternative cellular receptors. Cancer Res. 2002; 62: 4273-81.

34. Pong RC. Mechanism of increased coxsackie and adenovirus receptor gene expression and adenovirus uptake by phytoestrogen and histone deacetylase inhibitor in human bladder cancer cells and the potential clinical application. Cancer Res. 2006; 66: 8822-8. https://doi. org/10.1158/0008-5472.CAN-05-4672.
35. Watanabe T, Hioki M, Fujiwara T, Nishizaki M, Kagawa S, Taki M, Kishimoto H, Endo Y, Urata Y, Tanaka N. Histone deacetylase inhibitor FR901228 enhances the antitumor effect of telomerase-specific replication-selective adenoviral agent OBP-301 in human lung cancer cells. Exp Cell Res. 2006; 312: 256-65. https://doi.org/10.1016/j. yexcr.2005.10.026.

36. Watanabe Y, Hashimoto Y, Kagawa S, Kawamura H, Nagai K, Tanaka N, Urata Y, Fujiwara T. Enhanced antitumor efficacy of telomerase-specific oncolytic adenovirus with valproic acid against human cancer cells. Cancer Gene Ther. 2012; 19: 767-72.

37. Dong Z. Coxsackievirus and adenovirus receptor promotes antitumor activity of oncolytic adenovirus H101 in esophageal cancer. Int J Mol Med. 2012; 30: 1403-9. https://doi.org/10.3892/ijmm.2012.1133.

38. Bieler A, Mantwill K, Dravits T, Bernshausen A, Glockzin G, Köhler-Vargas N, Lage H, Gansbacher B, Holm PS. Novel three-pronged strategy to enhance cancer cell killing in glioblastoma cell lines: histone deacetylase inhibitor, chemotherapy, and oncolytic adenovirus d1520. Hum Gene Ther. 2006; 17: 55-70.

39. Hoti N, Chowdhury W, Hsieh J, Sachs M, Lupold S, Rodriguez R. Valproic acid, a histone deacetylase inhibitor, is an antagonist for oncolytic adenoviral gene therapy. Mol Ther. 2006; 14: 768-78. https://doi.org/10.1016/j. ymthe.2006.07.009.

40. de Jonge J, Berghauser Pont LM, Idema S, Kloezeman JJ, Noske D, Dirven CM, Lamfers ML. Therapeutic concentrations of anti-epileptic drugs do not inhibit the activity of the oncolytic adenovirus Delta24-RGD in malignant glioma: effects of antiepileptics on Delta24RGD. J Gene Med. 2013; 15: 134-41. https://doi.org/10.1002/ jgm.2703.

41. Biran A, Brownstein M, Haklai R, Kloog Y. Downregulation of survivin and aurora A by histone deacetylase and RAS inhibitors: a new drug combination for cancer therapy. Int J Cancer. 2011; 128: 691-701. https://doi.org/10.1002/ ijc. 25367.

42. Suzuki A, Kawano H, Hayashida M, Hayasaki Y, Tsutomi Y, Akahane K. Procaspase 3/p21 complex formation to resist fas-mediated cell death is initiated as a result of the phosphorylation of $\mathrm{p} 21$ by protein kinase A. Cell Death Differ. 2000; 7: 721-8. https://doi.org/10.1038/ sj.cdd.4400706.

43. Pospelova TV, Demidenko ZN, Bukreeva EI, Pospelov VA, Gudkov AV, Blagosklonny MV. Pseudo-DNA damage response in senescent cells. Cell Cycle. 2009; 8: 4112-8. https://doi.org/10.4161/cc.8.24.10215.

44. Huang X. Adenomatous polyposis coli determines sensitivity to histone deacetylase inhibitor-induced apoptosis in colon cancer cells. Cancer Res. 2006; 66: 9245-51. https://doi.org/10.1158/0008-5472.CAN-06-0887. 
45. Libertini S, Abagnale A, Passaro C, Botta G, Barbato S, Chieffi P, Portella G. AZD1152 negatively affects the growth of anaplastic thyroid carcinoma cells and enhances the effects of oncolytic virus d1922-947. Endocr Relat Cancer. 2011; 18: 129-41. https://doi.org/10.1677/ ERC-10-0234.

46. Connell CM, Wheatley SP, McNeish IA. Nuclear survivin abrogates multiple cell cycle checkpoints and enhances viral oncolysis. Cancer Res. 2008; 68: 7923-31. https://doi. org/10.1158/0008-5472.CAN-08-0817.

47. Ingemarsdotter CK, Baird SK, Connell CM, Öberg D, Hallden G, McNeish IA. Low-dose paclitaxel synergizes with oncolytic adenoviruses via mitotic slippage and apoptosis in ovarian cancer. Oncogene. 2010; 29: 6051-63.

48. Robert T, Vanoli F, Chiolo I, Shubassi G, Bernstein KA, Rothstein R, Botrugno OA, Parazzoli D, Oldani A, Minucci $\mathrm{S}$, Foiani M. HDACs link the DNA damage response, processing of double-strand breaks and autophagy. Nature. 2011; 471: 74-9. https://doi.org/10.1038/nature09803.

49. Stracker TH, Carson CT, Weitzman MD. Adenovirus oncoproteins inactivate the Mre11-Rad50-NBS1 DNA repair complex. Nature. 2002; 418: 348-52. https://doi. org/10.1038/nature00863.

50. Boyer J, Rohleder K, Ketner G. Adenovirus E4 34k and E4 $11 \mathrm{k}$ inhibit double strand break repair and are physically associated with the cellular DNA-dependent protein kinase. Virology. 1999; 263: 307-12. https://doi.org/10.1006/ viro.1999.9866.

51. Davoli T, de Lange T. The causes and consequences of polyploidy in normal development and cancer. Annu Rev Cell Dev Biol. 2011; 27: 585-610. https://doi.org/10.1146/ annurev-cellbio-092910-154234.

52. Baker A, Rohleder KJ, Hanakahi LA, Ketner G. Adenovirus E4 34k and E1b 55k oncoproteins target host DNA ligase IV for proteasomal degradation. J Virol. 2007; 81: 7034-40. https://doi.org/10.1128/JVI.00029-07.

53. Kachhap SK, Rosmus N, Collis SJ, Kortenhorst MS, Wissing MD, Hedayati M, Shabbeer S, Mendonca J, Deangelis J, Marchionni L, Lin J, Höti N, Nortier JW, et al. Downregulation of homologous recombination DNA repair genes by HDAC inhibition in prostate cancer is mediated through the E2F1 transcription factor. PLoS One. 2010; 5: e11208. https://doi.org/10.1371/journal.pone.0011208.

54. Shoji M, Ninomiya I, Makino I, Kinoshita J, Nakamura K, Oyama K, Nakagawara H, Fujita H, Tajima H, Takamura H, Kitagawa H, Fushida S, Harada S, et al. Valproic acid, a histone deacetylase inhibitor, enhances radiosensitivity in esophageal squamous cell carcinoma. Int J Oncol. 2012; 40: 2140-6. https://doi.org/10.3892/ijo.2012.1416.

55. Attwooll CL, Akpinar M, Petrini JH. The Mre11 complex and the response to dysfunctional telomeres. Mol Cell Biol. 2009; 29: 5540-51. https://doi.org/10.1128/MCB.00479-09.

56. Ciapponi L, Cenci G, Ducau J, Flores C, Johnson-Schlitz D, Gorski MM, Engels WR, Gatti M. The Drosophila Mre11/ Rad50 complex is required to prevent both telomeric fusion and chromosome breakage. Curr Biol. 2004; 14: 1360-6.

57. Martínez P, Blasco MA. Telomeric and extra-telomeric roles for telomerase and the telomere-binding proteins. Nat Rev Cancer. 2011; 11: 161-76. https://doi.org/10.1038/nrc3025.

58. Lamarche BJ, Orazio NI, Weitzman MD. The MRN complex in double-strand break repair and telomere maintenance. FEBS Lett. 2010; 584: 3682-95. https://doi. org/10.1016/j.febslet.2010.07.029.

59. Ahmed D, Eide PW, Eilertsen IA, Danielsen SA, Eknæs M, Hektoen M, Lind GE, Lothe RA. Epigenetic and genetic features of 24 colon cancer cell lines. Oncogenesis. 2013; 2: e71. https://doi.org/10.1038/oncsis.2013.35.

60. Vigne E, Dedieu JF, Brie A, Gillardeaux A, Briot D, Benihoud K, Latta-Mahieu M, Saulnier P, Perricaudet M, Yeh P. Genetic manipulations of adenovirus type 5 fiber resulting in liver tropism attenuation. Gene Ther. 2003; 10: 153-62. https://doi.org/10.1038/sj.gt.3301845.

61. Jullienne B, Vigant F, Muth E, Chaligné R, Bouquet C, Giraudier S, Perricaudet M, Benihoud K. Efficient delivery of angiostatin K1-5 into tumors following insertion of an NGR peptide into adenovirus capsid. Gene Ther. 2009; 16: 1405-15.

62. Benihoud K, Esselin S, Descamps D, Jullienne B, Salone B, Bobe P, Bonardelle D, Connault E, Opolon P, Saggio I. Respective roles of TNF- $\alpha$ and IL- 6 in the immune response-elicited by adenovirus-mediated gene transfer in mice. Gene Ther. 2007; 14: 533-44. 